Article

\title{
Optimal Segmentation over a Generalized Customer Distribution
}

\author{
Tsung-Yin Ou ${ }^{1,+}{ }^{\mathbb{C}}$, Yenming J. Chen ${ }^{2, *,+}+\mathbb{C}$ \\ 1 Department of Marketing, National Kaohsiung University of Science and Technology, Kaohsiung 813, Taiwan; \\ oupaul@nkust.edu.tw \\ 2 College of Management, National Kaohsiung University of Science and Technology, Kaohsiung 813, Taiwan \\ * Correspondence: yjjchen@nkust.edu.tw \\ + These authors contributed equally to this work.
}

Citation: Ou, T.-Y.; Chen, Y.J. Optimal Segmentation over a Generalized Customer Distribution. Axioms 2021, 10, 98. https://doi.org/ 10.3390 /axioms 10020098

Academic Editor: Faith-Michael E. Uzoka

Received: 11 March 2021

Accepted: 17 May 2021

Published: 21 May 2021

Publisher's Note: MDPI stays neutral with regard to jurisdictional claims in published maps and institutional affiliations.

Copyright: (c) 2021 by the authors. Licensee MDPI, Basel, Switzerland. This article is an open access article distributed under the terms and conditions of the Creative Commons Attribution (CC BY) license (https:// creativecommons.org/licenses/by/ $4.0 /)$.

\begin{abstract}
This paper investigates the impact of consumer preferences on the intensity of competition for companies in a duopoly market. A classical Hotelling's competition problem will be different if consumers are allowed to distribute non-uniformly. New results in competition intensity are established and conditions for the existence of a subgame perfect Nash equilibrium is identified through a model that considers generic distribution in consumer preferences. A competition strategy is demonstrated to depend on the signs of local change rates of the density function at the endpoints of market segments.
\end{abstract}

Keywords: heterogeneous customer preferences; Hotelling's competition; subgame perfect Nash equilibrium

\section{Introduction}

Complementing the classical debates on equilibrium, e.g., from d'Aspremont et al. [1], and supplementing the early discussions on consumer distribution, e.g., Shilony [2], this paper re-examines the best location problems from a fundamental perspective. We believe that scrutinizing the distribution pattern of consumers is necessary when performing market analysis. Given that the classical Hotelling's dispute disappears when consumers are not uniformly distributed, this study demonstrates the local properties for equilibrium under arbitrary consumer distribution.

Motivated by the debate of the smartphone market, this study contends that the implementation of a differentiation strategy is strongly dependent on the concentration of consumers. For example, smartphones are usually sold in screen sizes of 3.0, 4.0, 4.3, 4.7 , and 5.5 inches. If most consumers favor a 4.0-inch screen, the two duopolists will most likely change their products to 4.0-inch ones, as shown in Market A of Figure 1. If consumers are distributed in this single product, the classical dispute on maximal and minimal differentiation vanishes [2,3]. If half of the consumers like 4.0 inches and the other half like 4.7 inches, the two companies may differentiate themselves in two market segments, as shown in Market B of Figure 1. If consumers are randomly distributed, as shown in Market $C$ of Figure 1, companies may not choose locations as predicted by classical studies. In a conventional setup of spatial competition problems, consumers are assumed to equally prefer each variation of a product in the market, and the strategic choices of firms may be strongly influenced by the particular choice of the transportation cost function $[1,4,5]$. In a real-world market, consumers are unlikely to be equally attracted to all kinds of products.

A viable prediction of competition intensity should also be contingent on the consumer distribution of the market, rather than a sole factor of consumer utility or transportation cost function. The analytic model in this study assumes that consumers are generically distributed along a "linear city" and considers the balance of two factors, namely, consumer 
acceptance (utility surplus) and consumer distribution (sales potentials). As highlighted in Calvó-Armengol and Zenou [6] and Azar [7], positioning a product in a non-uniform market is essential in marketing research. However, despite the long history and versatile results of ala Hotelling differentiation models, the extant literature does not sufficiently provide suitable location strategies for addressing the case in which consumers are not uniformly distributed in all locations. The dual-channel competition with price sensitivity leads to low profit for a supply chain [8]. Cost-sharing contracts resolve channel conflict in asymmetric Nash bargaining products [9]. Shilony [2] suggests an existence condition for the equilibria of horizontal differentiation in which the demand distribution is confined within convex and concave distribution functions, and predicts that the equilibria should be located near the center of the uni-mode distribution density function. Neven [3] confirms that firms should closely position themselves towards the center of a concentrated market. Studies by de Palma et al. [10], Ansari et al. [11] and Rhee [12] develop alternative approaches where the purchase quantities of each product type are assumed to be random to represent the heterogeneity of consumer preferences. Their numerical results again confirm the previous conclusion that products will lie close as the market becomes concentrated. Despite these published studies, the location problems are analyzed under a restricted function form and no generic result has been found. This study offers a further understanding of the competition analysis on a generic consumer distribution.
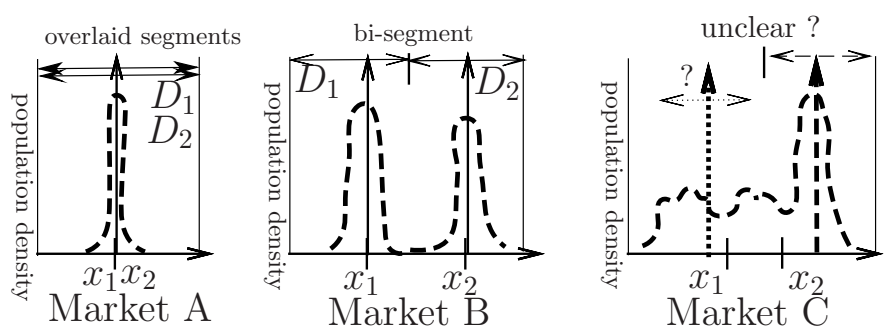

Figure 1. Intuition on the influence of consumer preference distribution on the differentiation strategy.

This study demonstrates the existence of subgame perfect Nash equilibrium under generic distribution in consumer preference. We find that competition intensity is affected by the signs of local change rates of the consumer distribution at the endpoints of consumer segments.

\section{Competition Model}

Consumer tastes are assumed to be distributed arbitrarily with a density function $f(x)$ along a market $[0,1]$, which is defined as $f(x) \triangleq \operatorname{Prob}[$ there is a customer at $x]$ for $x \in \mathcal{I}$ and $\mathcal{I}=[0,1]$. Differentiability for $f(\cdot)$ is assumed for ease of analysis, although we permit any form of the density function. A subdifferential or Ito differential can be considered in future research.

The game starts from a situation in which firms compete by selecting location $x_{i}$ and then determine the best price $p_{i}$ with consideration of the total amount of purchase $D_{i}\left(x_{i}, p_{i}\right)$. The locations assume that $x_{1} \leq x_{2}$ for notational convenience. A consumer receives a utility of $u_{i}(x)$ if purchasing from company $i$. A consumer $x$ makes a final decision to purchase from firm $i$ when $u_{i}(x) \geq u_{j}(x)$ and $u_{i}(x), u_{j}(x)>0$. The number of purchases accumulated in the covered market segment becomes the demand $D_{i}\left(x_{i}, p_{i}\right)$ for company $i$. The market segment or horizontal coverage is defined as follows:

$$
T_{i}=\left\{x: u_{i} \geq u_{j} \forall j, \text { and } u_{i}>0,\right\}=\left[\underline{x}_{i}\left(x_{i}, p_{i}\right), \bar{x}_{i}\left(x_{i}, p_{i}\right)\right] .
$$

The two-player game must involve competition to preclude triviality. The interactions disappear and no competition exists, if market segments do not overlap. Therefore, we assume that segments should be adjacent to one other. 
The classical Hotelling's model is challenged regarding the existence of equilibrium and suffers from discontinuity in the demand function. Figure 2A shows that the triangle shape of transportation cost functions gives rise to a possibility of discontinuity from line $\overline{A B}$ to $A^{\prime} B^{\prime}$, which is caused by the sudden change in the disappeared intersection between two parallel lines. A number of ala Hotelling models with many variations in the transportation function, such as the quadratic function, can effectively avoid discontinuity and have been proven to have equilibria [1].

In this study, the particular choice of the transportation cost function is barely considered but the influence of consumer distribution is especially important. Given the analysis goal, the transportation cost function should be as simple as possible. A simple cost function does not only make the mathematical derivation tamable, but also highlights the influence of the arbitrary function form. The linear transportation function is thus employed, but the slopes of functions must be different in order to maintain the differentiability of the resulting demand functions. The consumer utility $u_{i}$ is defined as $u_{i}\left(x ; x_{i}, p_{i}\right)=v-p_{i}-\theta_{i}\left|x-x_{i}\right|$, where $\theta_{i}$ is the cost of anti-preference in the location disparity. Figure $2 \mathrm{~B}$ shows that no sudden change in the intersection will be encountered if the triangles overlap properly. We establish the condition of equilibrium within an open set without having further restriction on decision variables. This open set is the neighborhood that excludes points in which the intersection of indifference points is non-existent.

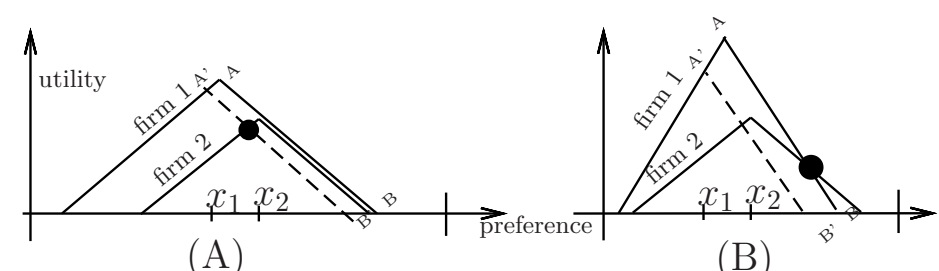

(A)

Figure 2. Classical Hotelling model suffers from the problem of discontinuity. Subfigure (A) shows that the triangle shape of transportation cost functions gives rise to a possibility of discontinuity from line $\overline{A B}$ to $A^{\prime} B^{\prime}$, which is caused by the sudden change in the disappeared intersection between two parallel lines. Subfigure (B) shows that no sudden change in the intersection will be encountered if the triangles overlap properly.

The expected demand and total profit for firm $i$ are given by

$$
D_{i}\left(x_{i}, p_{i}\right)=\int_{T_{i}\left(x_{i}, p_{i}\right)} f(x) d x
$$

and

$$
\pi_{i}\left(x_{i}, p_{i}\right)=D_{i}\left(x_{i}, p_{i}\right) p_{i}
$$

By Stokes' theorem, $D_{i}$ and $\pi_{i}$ become $D_{i}=\int_{T_{i}} d F=\int_{\partial T_{i}} F=F\left(\bar{x}_{i}\right)-F\left(\underline{x}_{i}\right)$, and $\pi_{i}\left(x_{i}, p_{i}\right)=\left[F\left(\bar{x}_{i}\right)-F\left(\underline{x}_{i}\right)\right] p_{i}$, respectively. The function $F(x)=\int_{0}^{x} f(t) d t$ is the distribution function of $f$, and $\underline{x}_{i}$ and $\bar{x}_{i}$ are the left and right endpoints, respectively. The values can be obtained by solving $v-p_{i}-\theta\left|x-x_{i}\right|=0$. We therefore have

$$
\underline{x}_{1}=\max \left\{x_{1}+\theta_{1}^{-1}\left(p_{1}-v\right), 0\right\}, \text { and } \bar{x}_{2}=\min \left\{x_{2}-\theta_{2}^{-1}\left(p_{2}-v\right), 1\right\} .
$$

The two segments must be adjacent to each other, because we exclude situations with no competition. In particular, $\bar{x}_{1}=\underline{x}_{2}=a$ is the indifference location, where $u_{1}(a)=u_{2}(a)$. Thus, $a=\frac{1}{\theta_{1}+\theta_{2}}\left(p_{2}-p_{1}+\theta_{1} x_{1}+\theta_{2} x_{2}\right)$.

\section{Location Analysis}

To characterize the property of consumer distribution, location and price equilibria are analyzed. Given the non-uniform distribution, we obtain results that are different from those of the previous analysis. 
Proposition 1. If the consumer distribution function $F$ is non-decreasing and concave, then the location-then-price subgame perfect Nash equilibrium $\left(x_{i}^{*}, p_{i}^{*}\right)$ exists and is unique.

Proof. Please see Appendix A for proof.

Proposition 1 requires the consumer distribution to be non-decreasing and concave. By definition, the distribution function is non-decreasing. This result differs from that of the original Hotelling's model. To be concave, the consumer preference density function $f(x)$ should at least be a non-increasing function. That is, the consumers who prefer a lower segment outnumber those who prefer a higher segment.

Proposition 2. If equilibrium locations $x_{1}^{*}$ and $x_{2}^{*}$ exist, market segmentation can be characterized by the indifferent location $a^{*}$ that satisfies

$$
\begin{array}{ll}
\text { (i) } & f(a)=2 f\left(\underline{x}_{1}\right)=2 f\left(\bar{x}_{2}\right) \text {, and } \\
\text { (ii) } \min \left\{F(a)-F\left(\underline{x}_{1}\right), F\left(\bar{x}_{2}\right)-F(a)\right\} \geq \frac{2}{\theta_{1}+\theta_{2}} f(a) .
\end{array}
$$

Please see Appendix A for the proof.

To rationalize the conditions in Propositions 1 and 2, we consider a situation in which two competing firms determine their best location in a market with non-uniform consumer distribution. If Firm 1 decides to produce a product that moves away from the center to occupy wider coverage, then consumers in the center become uninterested in Product 1 , such that Firm 2 will most likely take over the vacancy. By contrast, if most consumers are located at the center market, both firms decrease their coverage span and stay close to the center market. However, a concentration on the competition in the center market may leave the far-end markets uncovered. Therefore, in addition to conventional conditions in competition intensity, consumer distribution also determines the location strategy of a firm. Therefore, market segmentation relies on consumer distribution, competition intensity and cost in anti-preference.

We characterize consumer distribution in Condition (5). Steep changes in the consumer population give rise to narrow segments and a strong competitive market. However, if the consumer density is uniform, i.e., $f(\cdot)=1$, then having distinct $a, \underline{x}_{1}$ and $\bar{x}_{2}$, that satisfy $f(a)=2 f\left(\underline{x}_{1}\right)=2 f\left(\bar{x}_{2}\right)$, is impossible. Thus, this condition asserts that the classical Hotelling's model fails to find equilibrium in a linear city.

Proposition 2 demonstrates two necessary conditions to identify the nature of the equilibrium. Condition (5) excludes most situations in which the equilibria do not exist, which is similar to the case of uniform distribution. Condition (6) further characterizes the possible span of two market segments in equilibrium. Without this condition, an interval can be infinitely small. We now investigate the relationship of the anti-preference cost to the location strategies.

Proposition 3. The competition between two firms weakens when the cost of anti-preference increases, $\left.\frac{d\left(x_{2}-x_{1}\right)}{d \theta_{i}}\right|_{x_{1}=x_{1}^{*}, x_{2}=x_{2}^{*}}>0$, if

$$
\left[2 f^{\prime}\left(\underline{x}_{1}\right)-f^{\prime}(a)\right]\left[2 f^{\prime}\left(\bar{x}_{2}\right)-f^{\prime}(a)\right]>0,
$$

and

$$
\frac{\left(v-p_{1}\right)}{\left(v-p_{2}\right)}<\frac{f^{\prime}\left(\bar{x}_{2}\right)+f^{\prime}(a)}{f^{\prime}\left(\underline{x}_{1}\right)+f^{\prime}(a)}, \text { for } p_{1} \neq p_{2} .
$$

Please see Appendix A for the proof.

Condition (7) specifies the rates of changes in the consumer distribution function on the endpoints of market segments. Proposition 3 suggests that a higher anti-preference cost results in weaker competition, if the rates of changes of consumer density at the endpoints 
of market segments are either higher or lower than the rate at the center. Intuitively, the implication is true because consumers are unlikely to tolerate deviation from their true preferences. To retain the same segment length, equilibrium pricing should be decreased, and the location should be diversified. However, the maximum objectives may not be achieved under the same segment lengths, because the intuition involves a nonlinear optimizer, which is quadratic in price.

Proposition 4. The competition between two firms intensifies, $\left.\frac{\partial x_{1}}{\partial x_{2}}\right|_{x_{1}=x_{1}^{*}}<0$, if

$$
\left[2 f^{\prime}\left(\underline{x}_{1}\right)-f^{\prime}(a)\right]\left[2 f^{\prime}\left(\bar{x}_{2}\right)-f^{\prime}(a)\right]>0 .
$$

Conversely, $\left.\frac{\partial x_{1}}{\partial x_{2}}\right|_{x_{1}=x_{1}^{*}}>0$, if $\left[2 f^{\prime}\left(\underline{x}_{1}\right)-f^{\prime}(a)\right]\left[2 f^{\prime}\left(\bar{x}_{2}\right)-f^{\prime}(a)\right]<0$.

Please see Appendix A for the proof.

The findings in Proposition 4 are consistent with that of Shilony [2], except that we have captured the local properties of the consumer distribution. If the local rate of change in the density function of the endpoints has the same sign as the central point for the two adjacent segments, the location strategy should follow a minimal or maximal differentiation principle, as shown in Figure 3. A counteracting strategy is then recommended in the differentiation situation. Conversely, if the endpoints exhibit the opposite trend of changes in the density function, the location strategy follows a constant differentiation principle. A deterrence strategy is then employed to respond to the actions of the rival.

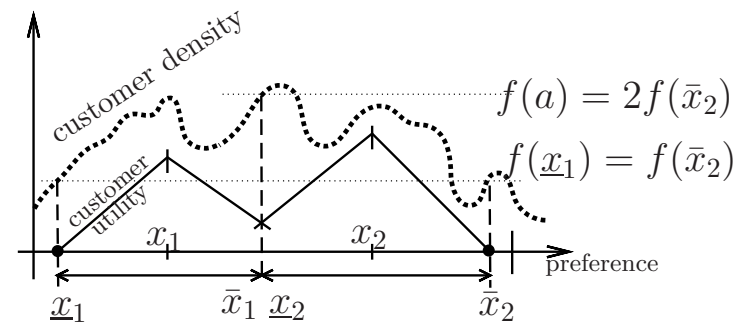

Figure 3. Differentiation strategy depending on the change rates of consumer density at the endpoints of the segments.

\section{Conclusions}

This study sheds new light on the necessity of considering the preference distribution of the consumer population. We show the condition in which the subgame perfect Nash equilibria exist when the consumer distribution function is arbitrary. Our analysis confirms that having SPNE is impossible for uniform distribution. We further provide two necessary conditions to characterize the equilibria, and suggest that the market can be bisected according to the local rates of the density function and the competition strategy. We suggest that a company should implement a minimal or maximal differentiation principle, if endpoints of consumer density function change in the same direction as the central point. Conversely, a company should implement a constant differentiation principle, if the directions are opposite.

This study offers an advantage for marketing managers. We clearly resolve the debate between differentiation and imitation for rival products. We successfully explain why some companies are profitable in selling imitative products but other companies fail in following competitors.

Although this study has relaxed the restricted function form of competitive strategies and offered further understanding of the competition analysis on a generic consumer distribution, the location problems still represent ample research topics for further analytics. 
Author Contributions: Conceptualization, T.-Y.O. and Y.J.C.; methodology, Y.J.C.; software, Y.J.C.; validation, T.-Y.O. and Y.J.C.; formal analysis, T.-Y.O. and Y.J.C.; investigation, T.-Y.O. and Y.J.C.; resources, T.-Y.O.; data curation, T.-Y.O.; writing-original draft preparation, T.-Y.O. and Y.J.C.; writing-review and editing, T.-Y.O. and Y.J.C.; visualization, T.-Y.O. and Y.J.C.; supervision, T.-Y.O.; project administration, T.-Y.O.; funding acquisition, T.-Y.O. All authors have read and agreed to the published version of the manuscript.

Funding: This research was funded by the Ministry of Science and Technology, Taiwan grant number 109-2625-M-020-002 and 109-2410-H-992-018-MY2.

Institutional Review Board Statement: Not applicable.

Informed Consent Statement: Not applicable.

Conflicts of Interest: The authors declare no conflict of interest.

\section{Appendix A. Theorem Proofs}

Proof. (Proof of Proposition 1.) Recall that $\pi_{i}\left(x_{i}, p_{i}\right)=p_{i} \int_{T_{i}} f(x) d x=p_{i} \int_{\partial T_{i}} F=$ $p_{i}\left(F\left(\bar{x}_{i}\right)-F\left(\underline{x}_{i}\right)\right)$. The indifference point $a=\frac{1}{2}\left(x_{1}+x_{2}+p_{2}-p_{1}\right)$. For the $x_{1}$ segment, $\pi_{1}\left(x_{1}, p_{1}\right)=\left\{\begin{array}{l}p_{1}\left[F\left(\bar{x}_{1}\right)-F\left(\underline{x}_{1}\right)\right], \quad \text { if } x_{1}-x_{2}<p_{2}-p_{1}<x_{2}-x_{1}, \\ p_{1}, \quad \text { if } p_{2}-p_{1} \geq x_{2}-x_{1} .\end{array}\right.$ To prove the existence and uniqueness of subgame perfect Nash equilibria, we need to prove the problem having the submodular property is enough $[13,14]$. Because the payoff functions are lower semi-continuous, we can prove our position-then-price subgame is submodular by checking the property of increasing difference. Let $v^{a}=\left(x_{1}, p_{1}, x_{2}, p_{2}\right)$, $v^{b}=\left(x_{1}^{\prime}, p_{1}^{\prime}, x_{2}^{\prime}, p_{2}^{\prime}\right)$ and $v^{a} \prec v^{b}$. We want to check the property of increasing difference $\pi_{1}\left(x_{1}^{\prime}, p_{1}^{\prime} ; x_{2}^{\prime}, p_{2}^{\prime}\right)-\pi_{1}\left(x_{1}, p_{1} ; x_{2}^{\prime}, p_{2}^{\prime}\right) \geq \pi_{1}\left(x_{1}^{\prime}, p_{1}^{\prime} ; x_{2}, p_{2}\right)-\pi_{1}\left(x_{1}, p_{1} ; x_{2}, p_{2}\right)$. If either $p_{2}-p_{1} \geq x_{2}-x_{1}$ or $p_{2}-p_{1} \leq x_{1}-x_{2}$, the function $\pi_{1}$ is either 0 or 1 , which satisfies the increasing difference properties. If $x_{1}-x_{2}<p_{2}-p_{1}<x_{2}-x_{1}$, it follows that the difference $\pi_{1}\left(x_{1}^{\prime}, p_{1}^{\prime} ; x_{2}^{\prime}, p_{2}^{\prime}\right)-\pi_{1}\left(x_{1}, p_{1} ; x_{2}^{\prime}, p_{2}^{\prime}\right)-\left(\pi_{1}\left(x_{1}^{\prime}, p_{1}^{\prime} ; x_{2}, p_{2}\right)-\pi_{1}\left(x_{1}, p_{1} ; x_{2}, p_{2}\right)\right)$ becomes

$$
\begin{aligned}
& \left(F\left(\frac{1}{\theta_{1}+\theta_{2}}\left(\left(\theta x_{1}-p_{1}+\theta x_{2}+p_{2}\right)\right)\right)-F\left(\frac{1}{\theta_{1}+\theta_{2}}\left(\left(\theta x_{1}-p_{1}+\theta x_{2}^{\prime}+p_{2}^{\prime}\right)\right)\right) p_{1}+\right. \\
& \left(F\left(\frac{1}{\theta_{1}+\theta_{2}}\left(\left(\theta x_{1}^{\prime}-p_{1}^{\prime}+\theta x_{2}^{\prime}+p_{2}^{\prime}\right)\right)\right)-F\left(\frac{1}{\theta_{1}+\theta_{2}}\left(\left(\theta x_{1}^{\prime}-p_{1}^{\prime}+\theta x_{2}+p_{2}\right)\right)\right)\right) p_{1}^{\prime} .
\end{aligned}
$$

If $F$ is monotonically non-decreasing and concave, from the subadditivity properties of $F$, we have

$$
\begin{aligned}
& F\left(\frac{1}{\theta_{1}+\theta_{2}}\left(\left(\theta x_{1}^{\prime}-p_{1}^{\prime}+\theta x_{2}^{\prime}+p_{2}^{\prime}\right)\right)\right)-F\left(\frac{1}{\theta_{1}+\theta_{2}}\left(\left(\theta x_{1}^{\prime}-p_{1}^{\prime}+\theta x_{2}+p_{2}\right)\right)\right) \leq \\
& F\left(\frac{1}{\theta_{1}+\theta_{2}}\left(\left(\theta x_{2}^{\prime}+p_{2}^{\prime}-\theta x_{2}+p_{2}\right)\right)\right) .
\end{aligned}
$$

It follows that the difference is greater than

$$
\begin{aligned}
& -F\left(\frac{1}{\theta_{1}+\theta_{2}}\left(\left(\theta x_{2}^{\prime}+p_{2}^{\prime}-\theta x_{2}+p_{2}\right)\right)\right) p_{1}+ \\
& \left(F\left(\frac{1}{\theta_{1}+\theta_{2}}\left(\left(\theta x_{1}^{\prime}-p_{1}^{\prime}+\theta x_{2}^{\prime}+p_{2}^{\prime}\right)\right)\right)-F\left(\frac{1}{\theta_{1}+\theta_{2}}\left(\left(\theta x_{1}^{\prime}-p_{1}^{\prime}+\theta x_{2}+p_{2}\right)\right)\right)\right) p_{1}^{\prime} .
\end{aligned}
$$

Because $p_{1}$ and $p_{1}^{\prime}$ are non-negative, the expression $-F\left(\frac{1}{\theta_{1}+\theta_{2}}\left(\left(\theta x_{2}^{\prime}+p_{2}^{\prime}-\theta x_{2}+\right.\right.\right.$ $\left.\left.p_{2}\right)\right) p_{1}+F\left(\frac{1}{\theta_{1}+\theta_{2}}\left(\left(\theta x_{2}^{\prime}+p_{2}^{\prime}-\theta x_{2}+p_{2}\right)\right)\right) p_{1}^{\prime}$ is sufficiently greater than the difference. Because $p_{1}^{\prime}>p_{1}$, the increasing difference property holds.

Proof. (Proof for Proposition 2.) Given that the price difference satisfies $\left|p_{2}-p_{1}\right|<x_{2}-x_{1}$, for all $p_{i}$ and $x_{i}$, the payoff functions are continuous differentiable. Let $\pi_{i}=\pi_{i}\left(x_{i}, p_{i}\left(x_{1}, x_{2}\right)\right)$. The total derivatives are 


$$
\begin{aligned}
& \frac{d \pi_{1}\left(x_{1}, p_{1}\left(x_{1}, x_{2}\right)\right)}{d x_{1}}=\left(\frac{1}{2} f(a)-f\left(\underline{x}_{1}\right)\right) p_{1}-\left(f(a)+\theta^{-1} f\left(\underline{x}_{1}\right)\right) p_{1} p_{1 x_{1}}+\left(F(a)-F\left(\underline{x}_{1}\right)\right) p_{1 x_{1}} \\
& \frac{d \pi_{2}\left(x_{2}, p_{2}\left(x_{1}, x_{2}\right)\right)}{d x_{2}}=\left(f\left(\bar{x}_{2}\right)-\frac{1}{2} f(a)\right) p_{2}-\left(f(a)+\theta^{-1} f\left(\underline{x}_{1}\right)\right) p_{2} p_{2 x_{2}}+\left(F\left(\bar{x}_{2}\right)-F(a)\right) p_{2 x_{2}}
\end{aligned}
$$

Because the cumulative distribution function $F(\cdot)$ is monotone, therefore, we have $p_{i}>0$ for all $i$. We then obtain the first necessary conditions

$$
\begin{aligned}
& \left(F(a)-F\left(\underline{x}_{1}\right)\right)\left(f(a)-2 f\left(\underline{x}_{1}\right)\right)=0, \\
& \left(F\left(\bar{x}_{2}\right)-F(a)\right)\left(2 f\left(\bar{x}_{2}\right)-f(a)\right)=0 .
\end{aligned}
$$

From the first part of the proof, we have derived the conditions for ensuring the existence of $p_{i}$. We know $p_{i}>0$ for all $i$ and by the condition $f(a)=2 f\left(\underline{x}_{1}\right)=2 f\left(\bar{x}_{2}\right)$ specified in (A1), we have

$$
\begin{aligned}
& F(a)-F\left(\underline{x}_{1}\right) \geq \frac{1}{2 p_{1 x_{1}} \theta}\left(\left(2\left(\theta_{1}+p_{1 x_{1}}\right)\right) f\left(\underline{x}_{1}\right)-2\left(\theta_{2}-p_{1 x 1}\right) f\left(\underline{x}_{1}\right)\right)=\frac{2}{\theta} f(a), \\
& F\left(\bar{x}_{2}\right)-F(a) \geq \frac{1}{2 p_{2 x_{2}} \theta}\left(2\left(\theta_{1}+p_{2 x_{2}}\right) f\left(\bar{x}_{2}\right)-2\left(\theta_{2}-p_{2 x_{2}}\right) f\left(\bar{x}_{2}\right)\right)=\frac{2}{\theta} f(a) .
\end{aligned}
$$

Proof. (Proof for Proposition 3.) Concatenating two contiguous intervals of (5), we have

$$
f\left(\underline{x}_{1}\right)-f(a)+f\left(\bar{x}_{2}\right)=0 .
$$

Write (A3) in terms of implicit function $G\left(x_{1}, x_{2}, \theta\right)$ and let $G=0$. The positioning strategy around the equilibrium can be analyzed by employing the implicit function theorem $\frac{\partial\left(x_{2}-x_{1}\right)}{\partial \theta_{1}}=-\frac{\partial G}{\partial \theta_{1}} / \frac{\partial G}{\partial x_{2}}+\frac{\partial G}{\partial \theta_{1}} / \frac{\partial G}{\partial x_{1}}$.

If $\frac{\left(v-p_{1}\right)}{\left(v-p_{2}\right)}<\frac{f^{\prime}\left(\bar{x}_{2}\right)+f^{\prime}\left(\underline{x}_{1}\right)}{f^{\prime}(a)+f^{\prime}\left(\underline{x}_{1}\right)}$, then the condition in the theorem is followed.

Proof. (Proof for Proposition 4.) Use the relation (A3) as the implication function. The positioning strategy around the equilibrium can be seen by employing the implicit function theorem $\frac{\partial x_{i}}{\partial x_{j}}=-\frac{\partial G}{\partial x_{2}} / \frac{\partial G}{\partial x_{1}}=\frac{\partial x_{i}}{\partial x_{j}}=-\frac{\partial G}{\partial x_{2}} / \frac{\partial G}{\partial x_{1}}=-\frac{-\frac{1}{2} f^{\prime}(a)+f^{\prime}\left(\bar{x}_{2}\right)}{f^{\prime}\left(\underline{x}_{1}\right)-\frac{1}{2} f^{\prime}(a)}$. The derivative $\frac{\partial x_{1}}{\partial x_{2}}>0$ if $\left(2 f^{\prime}\left(\bar{x}_{2}\right)-f^{\prime}(a)\right)\left(2 f^{\prime}\left(\underline{x}_{1}\right)-f^{\prime}(a)\right)<0$.

\section{References}

1. d'Aspremont, C.; Gabszewicz, J.; Thisse, J. On Hotelling's Stability in Competition. Econometrica 1979, 47, 1145-1150. [CrossRef]

2. Shilony, Y. Hotelling's competition with general customer distributions. Econ. Lett. 1981, 8, 39-45. [CrossRef]

3. Neven, D. On Hotelling's competition with non-uniform customer distributions. Econ. Lett. 1986, 21, 121-126. [CrossRef]

4. Economides, N. Quality variations and maximal variety differentiation. Reg. Sci. Urban Econ. 1989, 19, 21-29. [CrossRef]

5. Hou, H.; Wu, X.; Zhou, W. The competition of investments for endogenous transportation costs in a spatial model. Econ. Model. 2013, 31, 574-577. [CrossRef]

6. Calvó-Armengol, A.; Zenou, Y. The importance of the distribution of consumers in horizontal product differentiation. J. Reg. Sci. 2002, 42, 793-803. [CrossRef]

7. Azar, O. Can more consumers lead to lower profits? A model of multi-product competition. J. Econ. Behav. Organ. 2010, 76, 184-195. [CrossRef]

8. Giri, B.C.; Dey, S. Game theoretic models for a closed-loop supply chain with stochastic demand and backup supplier under dual channel recycling. Decis. Mak. Appl. Manag. Eng. 2020, 3, 108-125.

9. Panda, S.; Modak, N.M.; Cárdenas-Barrón, L.E. Does extended warranty depict competitive advantage to a retailer in a retail-e-tail channel supply chain. Comput. Ind. Eng. 2020, 149, 106770. [CrossRef]

10. de Palma, A.; Ginsburgh, V.; Papageorgiou, Y.; Thisse, J. The principle of minimum differentiation holds under sufficient heterogeneity. Econometrica 1985, 53,767-781. [CrossRef]

11. Ansari, A.; Economides, N.; Ghosh, A. Competitive positioning in markets with nonuniform preferences. Mark. Sci. 1994, 13, 248-273. [CrossRef]

12. Rhee, B. Consumer heterogeneity and strategic quality decisions. Manag. Sci. 1996, 42, 157-172. [CrossRef] 
13. Fujishige, S. Theory of submodular programs: A Fenchel-type min-max theorem and subgradients of submodular functions. Math. Program. 1984, 29, 142-155. [CrossRef]

14. Topkis, D. Supermodularity and Complementarity; Princeton University Press, Electronic: Princeton, NJ, USA, 1998. 